\title{
The role of multiple vessel Doppler ultrasound in predicting neonatal outcome in pregnancy induced hypertension
}

\author{
Vijay N. Gadhavi*, Mansi K. Gadhavi
}

Department of Obstetrics and Gynecology, C. U. Shah Medical College, Surendranagar, Gujarat, India

Received: 25 September 2018

Accepted: 16 October 2018

\section{*Correspondence:}

Dr. Vijay N. Gadhavi,

E-mail: drvijaygadhavi@gmail.com

Copyright: $\odot$ the author(s), publisher and licensee Medip Academy. This is an open-access article distributed under the terms of the Creative Commons Attribution Non-Commercial License, which permits unrestricted non-commercial use, distribution, and reproduction in any medium, provided the original work is properly cited.

\begin{abstract}
Background: Hypertensive disorders are among the commonest medical disorders during pregnancy and continue to be a major cause of maternal and perinatal morbidity and mortality.

Methods: In this study total 100 cases and their doppler findings were recorded, Cases of PIH between 20 - 36 weeks of gestation in 2 years with B.P $\geq 140 / 90 \mathrm{~mm}$ hg and protienuria $\geq 1+$ in this prospective analytical study investigations and color doppler scanner for studying uterine, umbilical PI, RI and fetal middle cerebral arteries as the indicator to evaluate perinatal outcome.

Results: Increase incidence of low birth weight (less than 2.5) observed in group of umbilical and uterine PI was $(>1.5,>1$ respectively) $67 \%$ and $83 \%$. Apgar score at 5 minutes $<758 \%$ and $61 \%$, NICU admission $46 \%$ and $45 \%$, perinatal mortality $42 \%$ and $45 \%$ respectively. for group of umbilical artery and uterine artery RI $(>0.7$, $>0.6$ respectively) newborn delivered with weight less than $2.5 \mathrm{~kg} 76 \%$ and $80 \%$, Apgar score at 5 minutes $<733 \%$ and $80 \%$, NICU admission $46 \%$ and 50\%, perinatal mortality $60 \%$ and $42 \%$ more than that of with group of low RI. High rate of incidence seen where MCA PI $<1.3,90 \%$ newborns less than $2.5 \mathrm{~kg}$ birth weight, $70 \%$ poor Apgar score at 5 minutes. abnormal ductus venosus group shows birth weight $<2.5 \mathrm{~kg} 83 \%$, Apgar at 5 minutes $<7$ were $81 \%$, NICU admission were $39 \%$ and perinatal mortalities $78 \%$ higher than normal ductus venosus group.

Conclusions: The sensitivity of the Doppler significantly increased by studying multiple vessels $(91.6 \%)$ of in the fetoplacental circulation. It would predict early compromise of blood supply to the fetus at the stage when the fetus is still not compromised and if timely measures are taken it helps in improvement of perinatal out-come.
\end{abstract}

Keywords: Apgar score, Perinatal mortality, Umbilical artery doppler, Uterine artery

\section{INTRODUCTION}

Normal pregnancy and normal delivery are two classic examples to diagnose in retrospect. only after a pregnancy ends uneventfully one can say that this one was 'normal'. an obstetrician in clinical practice is therefore always seeking for methods to predict conditions that can disturb the normalcy of an ongoing pregnancy. this can enable him to take steps to prevent or minimize the complications. ${ }^{1}$ Approximately, $7-10 \%$ of all pregnancies are complicated by some form of hypertensive disease. Incidence of pregnancy induced hypertension (PIH) in rural India is $10 \%$. It is a cause of death in $8 \%$ of all maternal deaths. Nearly 3 million low birth weight babies are born annually in India. It accounts for more than half of neonatal deaths. ${ }^{2}$ Acccording to park hypertensive disorders are responsible for 5-8 \% of all maternal deaths. ${ }^{3}$ Doppler sonographic applications in pregnancy are widely accepted functional methods of evaluating fetal wellbeing. flow velocity wave forms provide important information from the early stages of pregnancy to term. as applications proliferate, awareness of complexity of fetal and placental circulations, in normal pregnancy and in sequential response to compromise, has also grown. ${ }^{4}$ one of main aims of routine antenatal care is to identify the 'at risk' fetus in 
order to apply clinical interventions which could result in reduced perinatal morbidity. basic principle of Doppler ultrasound is Doppler effect. ${ }^{5}$ The Doppler effect is the phenomenon of observed changes in the frequency of energy wave transmission when the relative motion occurs between the source of transmission and the observer. The phenomenon bears the name of the discoverer, Johann Christian Andrews Doppler, Austrian mathematician and an eminent physicist. Information obtained with Doppler sonography helps obstetricians managing patients in situations like pregnancies complicated by intrauterine growth restriction (IUGR), Rhesus alloimmunization, multiple pregnancies, and anamnestic risk factors. Examination of the uteroplacental and fetomaternal circulation by Doppler sonography in the early second trimester helps predicting pregnancy complications like preeclampsia, IUGR and perinatal death. ${ }^{1,6-14}$ Analysis of waveform provides a qualitative measurement of the resistance to flow in vessels that are being examined. Thus, Doppler flow studies help in making the decision regarding the management of fetus complicated by IUGR. With the introduction of Doppler Ultrasound examination, it became possible to assess the uteroplacental blood flow, feto placental blood flow and to assess the fetal blood circulation. The uteroplacental and fetoplacental circulation give information on the placental resistance whereas evaluating the fetal circulation using Doppler ultrasound could non-invasively assess the fetal response to hypoxia. This is become possible to identify those small fetuses that were at increased risk of perinatal morbidity and mortality due to impaired uteroplacental and fetoplacental circulations.

\section{METHODS}

The present study is conducted in the department of obstetrics and gynecology, C.U Shah medical college and Hospital, Surendranagar Saurashtra university, Gujarat. The study design is prospective analytical study. This study was conducted during the period from May 2011 to April 2013. Cases of PIH between 20-36 weeks of gestation will be studied over a period of 2 years having B.P $\geq 140 / 90 \mathrm{~mm} \mathrm{hg}$ and protienuria $\geq 1+$ in this prospective analytical study investigations and color doppler scanner with TA and TV probe will be used for studying uterine, umbilical and fetal middle cerebral arteries and placental changes like morphological as well as histological changes are observed. Authors use PI, RI of umbilical and uterine artery along with middle cerebral artery PI as the indicator to evaluate perinatal outcome. A total 100 women are included in the study

\section{Inclusion criteria}

- All Pregnancy beyond 20 weeks of gestation having Systolic BP >140 $\mathrm{mmHg}$, diastolic BP >90 mmHg on two occasions four hours apart in previously normotensive woman with Proteinuria $\geq 1+$ on Urine dip stick test.

\section{Exclusion criteria}

- Molar pregnancies

- Renal disease

- Chronic hypertension

- Hematological diseases

- Other causes of seizures

- Heart disease including IHD.

Prior to the commencement of the study ethical clearance was obtained from the Institutional Ethical committee, C.U Shah Medical college, Surendranagar, Gujarat. Pregnant women between 20-36 weeks of gestation attending antenatal clinic were screened for eligibility by detailed history, antenatal examination and investigations by trained residents in Department of Obstetrics and Gynecology. Women fulfilling selection criteria are explained about the purpose of the study and the need for randomization. A written informed consent was obtained from all participants before the enrollment than demographic data, obstetric history and current pregnancy details were obtained. The data was recorded on predesigned and pretested proforma

\section{RESULTS}

In present study it has been observed that in group of Umbilical artery PI more than 1.5 had new-borns delivered with weight less than $2.5 \mathrm{~kg} 67 \%$ while Apgar score at 5 minutes $<758 \%$, NICU admission $37 \%$, perinatal mortality $42 \%$ were more than that of with umbilical PI less than 1.5 group same as for group of umbilical artery RI more than 0.7 had new-born delivered with weight less than $2.5 \mathrm{~kg} 76 \%$ while Apgar score at 5 minutes $<733 \%$, NICU admission $46 \%$, perinatal mortality $60 \%$ were more than that of with umbilical RI less than 0.7 group.

Table 1: Percentage of birth weight $<2.5 \mathrm{~kg}$, Apgar at 5 minutes $<7$, NICU admission, perinatal mortality in group of umbilical artery PI $>1.5$ and $<1.5$.

\begin{tabular}{|lllll|}
\hline Umbilical artery PI & Birth weight $<2.5 \mathrm{~kg}$ & Apgar at 5 mins $<7$ & NICU admission & Perinatal mortality \\
\hline$>1.5(\mathrm{n}=43)$ & $29(67 \%)$ & $25(58 \%)$ & $16(37 \%)$ & $18(42 \%)$ \\
\hline$<1.5(\mathrm{n}=57)$ & $36(63 \%)$ & $26(46 \%)$ & $27(47 \%)$ & $11(19 \%)$ \\
\hline
\end{tabular}


Table 2: Percentage of birth weight $<2.5 \mathrm{~kg}$, Apgar at $5 \mathrm{mins}<7$, NICU admission, perinatal mortality in group of umbilical artery $\mathrm{RI}>0.7$ and $<0.7$.

\begin{tabular}{|lllll|}
\hline Umbilical artery RI & Birth weight $<2.5 \mathrm{~kg}$ & Apgar at 5 mins $<7$ & NICU admission & Perinatal mortality \\
\hline$>0.7(\mathrm{n}=78)$ & $59(76 \%)$ & $26(33 \%)$ & $36(46 \%)$ & $47(60 \%)$ \\
\hline$<0.7(\mathrm{n}=22)$ & $9(41 \%)$ & $3(14 \%)$ & $7(32 \%)$ & $0(0 \%)$ \\
\hline
\end{tabular}

Table 3: Percentage of birth weight $<2.5 \mathrm{~kg}$, Apgar at $5 \mathrm{mins}<7$, NICU admission, perinatal mortality in group of uterine artery $\mathrm{PI}>\mathbf{1 . 0}$ and $<\mathbf{1 . 0}$.

\begin{tabular}{|lllll}
\hline Uterine Artery PI & Birth weight $<2.5 \mathrm{~kg}$ & A pgar at 5 Mins $<7$ & NICU Admission & Perinatal mortality \\
$>1.0(\mathrm{n}=65)$ & $54(83 \%)$ & $40(61 \%)$ & $29(45 \%)$ & $29(45 \%)$ \\
\hline $1.0(\mathrm{n}=35)$ & $14(40 \%)$ & $9(26 \%)$ & $15(43 \%)$ & $0(0 \%)$
\end{tabular}

In present study it has been observed that in group of Umbilical artery PI more than 1.5 had newborns delivered with weight less than $2.5 \mathrm{~kg} 67 \%$ while Apgar score at 5 minutes $<758 \%$, NICU admission $37 \%$, perinatal mortality $42 \%$ were more than that of with umbilical PI less than 1.5 group. Same as in this study it has been observed that in group of umbilical artery RI more than 0.7 had newborns delivered with weight less than $2.5 \mathrm{~kg} \mathrm{76 \%}$ while Apgar score at 5 minutes $<733 \%$, NICU admission $46 \%$, perinatal mortality $60 \%$ were more than that of with umbilical RI less than 0.7 group. In this study it has been observed that in group of uterine artery PI more than 1 had newborns delivered with weight less than $2.5 \mathrm{~kg} 83 \%$ while Apgar score at 5 minutes $<761 \%$, NICU admission $45 \%$, perinatal mortality $45 \%$ were more than that of with uterine artery PI less than 1 group.
In present study it has been observed that in group of uterine artery RI more than 0.6 had newborns delivered with weight less than $2.5 \mathrm{~kg} 80 \%$ while Apgar score at 5 minutes $<761 \%$, NICU admission $50 \%$, perinatal mortality $42 \%$ were more than that of with uterine artery RI less than 0.6 group. It has been observed that in group of MCA (Middle Cerebella Artery) PI less than 1.3 had newborns delivered with weight less than $2.5 \mathrm{~kg} 90 \%$ while Apgar score at 5 minutes less $<770 \%$, NICU admission $40 \%$, perinatal mortality $68 \%$ were more than that of group with MCA PI more than 1.3. Doppler findings of ductus venosus stated that in group of birth weight $<2.5 \mathrm{~kg}$ were $30(83 \%)$, Apgar at 5 mins $<7$ were 29 (81\%), NICU admission were $14(39 \%)$ and perinatal mortalities were $28(78 \%)$ which were higher than normal ductus venosus group.

Table 4: Percentage of birth weight $<2.5 \mathrm{~kg}$, Apgar at 5 mins $<7$, NICU admission, perinatal mortality in group of uterine artery $\mathrm{RI}>0.6$ and $<0.6$.

\begin{tabular}{|lllll} 
Uterine artery RI & Birth weight $<2.5 \mathrm{~kg}$ & Apgar at 5 mins $<7$ & NICU admission & Perinatal mortality \\
$>0.6(\mathrm{n}=69)$ & $55(80 \%)$ & $42(61 \%)$ & $31(50 \%)$ & $29(42 \%)$ \\
$<0.6(\mathrm{n}=31)$ & $7(23 \%)$ & $6(19 \%)$ & $12(39 \%)$ & $0(0 \%)$
\end{tabular}

Table 5: Percentage of birth weight $<2.5 \mathrm{~kg}$, Apgar at 5 mins $<7$, NICU admission, perinatal mortality in group of MCA PI $>1.3$ and $<1.3$.

\begin{tabular}{|lllll|}
\hline MCA PI & Birth weight $<2.5 \mathrm{Kg}$ & Apgar at 5 mins $<7$ & NICU admission & Perinatal mortality \\
\hline$>1.3(\mathrm{n}=60)$ & $32(53 \%)$ & $21(35 \%)$ & $27(45 \%)$ & $02(3 \%)$ \\
$<1.3(\mathrm{n}=40)$ & $36(90 \%)$ & $28(70 \%)$ & $16(40 \%)$ & $27(68 \%)$ \\
\hline
\end{tabular}

Table 6: Percentage of birth weight $<2.5 \mathrm{~kg}$, Apgar at $5 \mathrm{mins}<7$, NICU admission, perinatal mortality in group of ductus venous doppler.

\begin{tabular}{lllll} 
Ductus venosus Doppler & Birth weight $<2.5 \mathrm{~kg}$ & A pgar at 5 mins $<7$ & NICU admission & Perinatal mortality \\
Abnormal $(\mathrm{n}=36)$ & $30(83 \%)$ & $29(81 \%)$ & $14(39 \%)$ & $28(78 \%)$ \\
\hline Normal $(\mathrm{n}=64)$ & $32(50 \%)$ & $19(30 \%)$ & $29(45 \%)$ & $2(3 \%)$
\end{tabular}


It is seen that in group of uterine artery PI more than 1 had new-borns delivered with weight less than $2.5 \mathrm{~kg}$ $83 \%$ while Apgar score at 5 minutes $<761 \%$, NICU admission $45 \%$, perinatal mortality $45 \%$ were more than that of with uterine artery PI less than 1 group while uterine artery RI more than 0.6 had new-borns delivered with weight less than $2.5 \mathrm{~kg} 80 \%$ while Apgar score at 5 minutes $<761 \%$, NICU admission $50 \%$, perinatal mortality $42 \%$ were more than that of with uterine artery RI less than 0.6 group. It has been observed that in group of MCA PI less than 1.3 had new-borns delivered with weight less than $2.5 \mathrm{~kg} 90 \%$ while Apgar score at 5 minutes $<7 \quad 70 \%$, NICU admission $40 \%$, perinatal mortality $68 \%$ were more than that of group with MCA PI more than 1.3. In present study abnormal ductus venosus Doppler had birth weight $<2.5 \mathrm{~kg}$ were 30(83\%), Apgar at 5 minutes < 7 were 29 (81\%), NICU admission were 14(39\%)and perinatal mortalities were $28(78 \%)$ higher than normal ductus venosus group birth weight $<2.5 \mathrm{~kg} 32$ (50\%),Apgar at 5 minutes $<7 \quad 19$ (30\%), NICU admission $29(45 \%)$ and perinatal mortality were $2(3 \%)$

\section{DISCUSSION}

In this study total 100 cases were observed; their Doppler findings was correlated with its perinatal outcome. Doppler velocimetry is primary non-invasive tool for fetomaternal condition in high risk pregnancy like PIH.

Table 7: Comparison of present study results with other studies.

\begin{tabular}{|lllll|}
\hline Studies & Birth weight $<2.5 \mathrm{~kg}$ & A pgar at 5<7 & NICU admission & Perinatal mortality \\
\hline Present study & $83 \%$ & $62 \%$ & $45 \%$ & $45 \%$ \\
\hline B N Lakhkar et al ${ }^{17}$ & $84 \%$ & $68 \%$ & $66 \%$ & $21 \%$ \\
\hline Lavnaya Rai et al $^{18}$ & $100 \%$ & $74 \%$ & $85 \%$ & $25 \%$ \\
\hline
\end{tabular}

In umbilical artery PI $>1.5$ incidence of low birth weight was more that was $67 \%$, Apgar $<7$ at 5 mins are $58 \%$, while perinatal mortality were around $42 \%$. As in Domenico Arduini et al and Giuseppe Rizzo et al study that fetuses who developed growth restriction showed higher value of PI in umbilical artery and study done by Karsdorp $\mathrm{VH}$ et al group with absent diastolic flow overall perinatal mortality rate was $28 \%$ and $11 \%$ with reversed flow and hence forth significantly more neonates with absent or reversed flow needed NICU admission. ${ }^{15,16}$

In abnormal uterine PI $>1$ birth weight $<2.5 \mathrm{~kg}$ was $83 \%$, Apgar $<7$ at 5 minute, $62 \%$ and NICU admission and perinatal mortality was $45 \%$ it was comparable with study of B N Lakhkar et al and Lavnaya Rai et al which observed that with abnormal uterine PI birth weight $<2.5$ $\mathrm{kg}$ was $84 \%$ and $100 \%$, Apgar $<7$ at 5 minute $68 \%$ and $74 \%$ while NICU admission was $66 \%$ and $85 \%$ and perinatal mortality was $21 \%$ and $25 \%$ respectively. ${ }^{17,18}$ In Present study of MCA $<1.3$ group shows that $90 \%$ fetus having birth weight $<2.5 \mathrm{~kg}, 70 \%$ having Apgar $<7$ at 5 minutes , $40 \%$ having NICU admission and perinatal mortality $67 \%$ which was consistent with study of Neilson JP et al contained Doppler ultrasound studies of the human fetal circulation have shown that in fetuses with IUGR there is a significant reduction of middle cerebral arterial (MCA) pulsatility index when compared with those in normal fetuses. ${ }^{19}$

Study shows that Doppler findings of ductus venosus suggest that in group of birth weightt $<2.5 \mathrm{~kg}$ were 30 $(83 \%)$, Apgar at 5 minutes $<7$ were $29(81 \%)$, NICU admission were $14(39 \%)$ and perinatal mortalities were
$28(78 \%)$ while in normal ductus venosus group birth weight $<2.5 \mathrm{~kg}$ were $32(50 \%)$, Apgar at 5 minutes $<7$ were $19(30 \%)$, NICU admission $29(45 \%)$ and perinatal mortality were $2(3 \%)$ that suggests that abnormal ductus venosus finding in Doppler that is zero or reversal of flow suggests untoward outcome and compromised fetal hemodynamic and very late to intervene to have better outcome of newborn.

\section{CONCLUSION}

Color Doppler is an excellent tool for non-invasive hemodynamic monitoring of PIH patients. Doppler ultrasound has been used in obstetrics to study the fetoplacental (umbilical) circulation and to study the uteroplacental (uterine) circulation and fetal circulation recently this method became an important tool for qualifying pregnancies in risk. It helps to identify the fetuses at risk and predict perinatal morbidity and mortality.

Present study was be done to assess the role of multiple vessel Doppler ultrasound in predicting neonatal outcome in pregnancy induced hypertension. Accumulated data reveal that there is a strong association between abnormal Doppler finding and Fetal growth retardation and early diagnosis of an adverse prenatal outcome in high-risk pregnancies like Pregnancy Induced Hypertension.

The timely diagnosis of fetal compromise by various fetal surveillance tests and intervention at an appropriate time before the fetus suffers irreversible damage like intrauterine fetal death is an important measure in decreasing the perinatal mortality. 
Funding: No funding sources

Conflict of interest: None declared

Ethical approval: The study was approved by the Institutional Ethics Committee

\section{REFERENCES}

1. Desai P. Predicting Obstetric Vasculopathies through Study of Diastolic Notch and other Indices of Resistance to Blood Flow in Uterine Artery. Int J Infertility Fetal Med. 2013;4(1):24-30.

2. Government of India; 2002-Annual report 20012002. Available at: http://planningcommission.nic.in/reports/genrep/arep 0102/ar01_02.pdf

3. Park K. Park's textbook of preventive and social medicine. Preventive Medicine in Obstet, $22^{\text {nd }} \mathrm{Ed}$. Paediatrics and Geriatrics. 2005.480-562

4. Harman CR, Baschat AA. Comprehensive assessment of fetal wellbeing: which Doppler test should perform? Curr Opin Clinical Obstet Gynecol. 2003;15(2):147-57.

5. Echizenya N, Kagupa D., Tachizaki, Saito YT; Significance of velocimetry as a monitor of fetal assessment and management; Fetal Diag Ther, 1989;4(4):188.

6. Bower S, Schuchter K, Campbell S; Doppler ultrasound screening as part of routine antenatal scanning: Prediction of pre-eclampsia and intrauterine growth retardation. Brit J Obstet Gynecol. 1993;100(11):989-94.

7. Caforio L, Testa AC, Mastromarino C, Carducci B, Ciampelli M, Mansueto D, Caruso A. Predictive value of uterine artery velocimetry at midgestation in low-and high-risk populations: a new perspective. Fetal Diag Ther. 1999;14(4):201-5.

8. Campbell S, Pearce JM, Hackett G, Cohen-Overbeek T, Hernandez C. Qualitative assessment of uteroplacental blood flow: early screening test for high-risk pregnancies. Obstet Gynecol. 1986;68(5):649-53.

9. Harrington K, Cooper D, Lees C, Hecher K, Campbell S. Doppler ultrasound of the uterine arteries: the importance of bilateral notching in the prediction of pre-eclampsia, placental abruption or delivery of a small-for-gestational-age baby. Ultrasound in Obstetrics and Gynecology: The Official J Int Society Ultra Obstet Gynecol. 1996;7(3):182-8.

10. Harrington K, Goldfrad C, Carpenter RG, Campbell S. Transvaginal uterine and umbilical artery Doppler examination of 12-16 weeks and the subsequent development of pre-eclampsia and intrauterine growth retardation. Ultra Obstet Gynecol. 1997;9(2):94-100.
11. Hoffmann H, Chaoui R, Bollmann R, Bayer H. Potential clinical application of Doppler ultrasound in obstetrics, Zentralbl Gynecology 1989; 111(19):1277-84.

12. Irion $\mathrm{O}$, Massé J, Forest JC, Moutquin JM. Prediction of preeclampsia, low birth weight for gestation and prematurity by uterine artery blood flow velocity waveforms analysis in low risk nulliparous women. $\mathrm{Br} \quad \mathrm{J}$ Obstet Gynecol. 1998;105(4):422-29.

13. Trudinger BJ, Giles WB, Cook CM. Uteroplacental blood flow velocity-time waveforms in normal and complicated pregnancy. Br J Obstet Gynecol 1985; 92(1):39-45.

14. Zimmermann P, Eiriö V, Koskinen J, Kujansuu E, Ranta T. Doppler assessment of the uterine and uteroplacental circulation in the second trimester in pregnancies at high risk for pre-eclampsia and/or intrauterine growth retardation: comparison and correlation between different Doppler parameters. Ultra Obstet Gynecol. 1997;9(5):330-8.

15. Arduini D, Rizzo G, Romanini C. Changes of pulsatility index from fetal vessels preceding the onset of late decelerations in growth retarded fetuses. Obstet Gynecol. 1992;79:605-10.

16. Karsdorp VH, van Vugt JM, van Geijn HP, Kostense $\mathrm{PJ}$, Arduim D, Montenegro $\mathrm{N}$, et al. Clinical significance of absent or reversed end diastolic velocity waveforms in umbilical artery. Lancet. 1994;344:1664.

17. Lakhkar BN, Rajagopal KV, Gourisankar PT. Doppler prediction of adverse perinatal outcome in PIH and IUGR. Ind J Radiol Imag. 2006;16(1):10916.

18. Rai L, Lekshmi S. Value of third trimester uterine artery doppler in high-risk pregnancies for prediction of adverse perinatal outcome. J South Asian Fed Obstet Gynecol. 2010;2(1):31-5.

19. Neilson JP, Alfirevic Z. Doppler ultrasound in highrisk pregnancies. In: Neilson JP, Crowther CA, Hodnett ED, Hofmeyr GJ, Keirse MJNC, eds. Pregnancy and childbirth module of the Cochrane database of systematic reviews. Available in Cochrane Library database on disk and CD-ROM, issue 3.

Cite this article as: Gadhavi VN, Gadhavi MK. The role of multiple vessel Doppler ultrasound in predicting neonatal outcome in pregnancy induced hypertension. Int J Reprod Contracept Obstet Gynecol 2018;7:4388-92. 